\title{
Contribuição do dipositivo de grupo na produção de saúde mental dos familiares de dependentes quimicos
}

\section{Contribution group health mental production of dependent chemical family}

DOI: $10.46919 / \operatorname{archv1n6-016}$

Recebimento dos originais: 01/09/2020

Aceitação para publicação: 30/10/2020

\section{Andréa Mata Machado Fernandes Dias}

Formação acadêmica mais alta: Graduação em psicologia. Pós graduação (especialização) Saúde mental álcool e outras drogas- Unb

Instituição de atuação atual: Unidade Básica de saúde sus/ses DF

- e Centro de Atenção Psicossocial Álcool e outras Drogas

Endereço completo: QD 107, lote 2 e 4 bloco A 1004

Aguas claras DF

E-mail: andreamatamachado12@gmail.com

\begin{abstract}
RESUMO
Neste artigo, tendo por base o estudo descritivo do grupo de familiares em um centro de atenção psicossocial aos usuários de álcool e outras drogas, é apresentado o conceito de substância química e dependência abordando o seu impacto na saúde mental dos familiares de dependentes químicos. Busca identificar o potencial terapêutico do grupo de familiares na produção de saúde mental, destacando como potencializadores aspectos referentes ao acolhimento do sofrimento, identificação grupal, troca de experiência, ajuda mútua e compreensão da dependência. Apresenta os efeitos positivos da abordagem de grupo para os familiares e conclui que esse tipo de intervenção vem sendo paulatinamente reconhecido nas politicas e programas de saúde mental e que estudos confirmam sua importância. Contudo é preciso maior incentivo e fomento de pesquisas a cerca da intervenção familiar que possam subsidiar os programas de saúde mental e contribuir nas ações realizadas na atenção psicossocial.
\end{abstract}

Palavras-chave: Dependência química, Família, Grupo de familiares.

\begin{abstract}
This paper presents the concept of chemical substance addiction and addressing its impact on mental health of family members of addicts. Seeks to identify the therapeutic potential of the family group in the mental health production. Highlighting aspects as boosters for the acceptance of suffering, group identification, exchange of experience, mutual help and understanding of addiction. Shows the positive effects of group approach to family members. Concludes that this type of intervention has been recognized in political and mental health programs. Studies confirm its importance. However we must further encourage and promote research about the family intervention to support mental health programs and contribute in the actions carried out in psychosocial care.
\end{abstract}

Keywords: Chemical dependency, Family, Family group. 


\section{DROGAS E DEPENDENCIA QUIMICA: CONCEITUAÇÃO E CARACTERIZAÇÃO}

O Ministério da Saúde conceitua drogas como substancia psicoativa ou psicotrópica que produzem alterações no sistema nervoso central do individuo e consequentemente nos seus padrões comportamentais e emocionais. Dalgalarrondo (2008) define a substância psicoativa como qualquer substancia química, que quando ingerida, modifica uma ou varias funções do sistema nervoso central produzindo efeitos psíquicos e comportamentais produzindo de modo geral, uma sensação de prazer ou excitação.

A dependência de substancia psicoativa é definida como um padrão mal adaptativo de uso de substancia em que há repercussões psicológicas, físicas e sociais que resultam da interação entre o ser humano e uma substancia psicoativa. Há na dependência, um grande envolvimento do sujeito com a substância psicoativa; ele gasta muito tempo (e interesse afetivo) em atividades que impliquem a obtenção ou consumo da substancia (Dalgalarrondo 2008). A dependência pode ser compreendida como um comportamento no qual o individuo abandona sua vida para refugiar-se na sua própria dependência, sacrificando seu conforto, sua segurança, seus afetos pelo comportamento aditivo (SEADI 2007). Por sua complexidade, pode se compreendida como uma doença biopsicossocial, pois é influenciada por fatores orgânicos, psíquicos, sociológicos e culturais.

\section{IMPACTO DA SUBSTANCIA PSICOATIVA NOS FAMILIARES DE DEPENDENTEQUIMICO.}

O uso da substancia psicoativa pelo homem não é fato recente, remete as civilizações mais antigas podendo ser considerada uma prática milenar e universal. Na atualidade, o crescente aumento do uso de substancias licita e ilícita tornou-se um dos maiores problemas de saúde mundial. De acordo com a organização mundial de saúde (OMS) cerca de $10 \%$ das populações dos centros urbanos de todo o mundo consomem abusivamente substancias psicoativas independente da idade, sexo, nível de instrução e poder aquisitivo (BRASIL. 2003).

No Brasil a realidade é preocupante. Segundo dados do levantamento domiciliar realizado pelo CERBRID em 2005 (Carlini et al, 2005) 22,8\% da população já fizeram uso na vida (qualquer tipo de uso inclusive o experimental) de drogas, exceto álcool e tabaco. A estimativa de dependentes de álcool no mesmo período foi de 12,3\% e de tabaco 10,01\%. Segundo dados do levantamento da CEBRID (2005), de $9 \%$ a $11 \%$ das pessoas entre 12 a 65 anos são dependentes de álcool.

A dependência de substancias psicoativa como o padrão de consumo em alguns casos acarretam prejuízos para o individuo no plano físico, clínico, afetivo, social e familiar. O sofrimento decorrente da 
dependência não restringe apenas ao sujeito, mas repercute em sua família além de poder desencadear diversas situações de vulnerabilidade.

Cavalheri (2010) menciona que a vivência com a enfermidade, seja ela de ordem física ou psiquiátrica, é algo complexo e exaustivo para os familiares. Essa situação exaustiva se eleva quando a doença é de longa duração, reincidente em suas manifestações agudas e experienciada como estigmatizadora e incapacitante. O estudo de Maciel e et al (2014) aponta que as condições que geram uma sobrecarga emocional, física e econômica modificam o funcionamento familiar e agrava a saúde, a vida social, as relações entre familiares, o lazer, a situação econômica, o desempenho profissional, as atividades domésticas e outros aspectos da vida.

A convivência com a dependência química expõe os familiares dos usuários de drogas a situações estressantes, muitas vezes por um longo período de tempo, o que pode afetar sua saúde física e mental como a manifestação de sintomas depressivos e ansiosos.

Ansiedade popularmente descrita como nervosismo, agonia, choquinho na cabeça, é definida por Dalgalarrondo (2008, p.166) “como estado de humor desconfortável, apreensão negativa em relação ao futuro, inquietação interna desagradável inclui manifestações somáticas e fisiológicas tais como: dispneia, taquicardia, vaso constrição ou dilatação, tensão muscular sudorese, tontura”. Perpassa pelos seguintes sintomas mentais: inquietação interna, medo difuso e impreciso, apreensão desagradável, preocupações exageradas insegurança, irritabilidade, dificuldade para concentrar, insônia.

O termo ansiedade e angustia podem aparecer como sinônimo na literatura clinica. De acordo com Deglarronde (2008, p.166) há diferenças sutis entre tais conceitos:

Do ponto de vista existencial a angustia tem significado mais marcante, é algo que define a condição humana, é um tipo de vivencia mais pesada, mais fundamental que a experiência de ansiedade. Angustia remete a sensações mais corporais como: aperto no peito, nó na garganta, sufocamento.

Deglarronde ressalta ainda que o medo refere-se a um objeto mais ou menos preciso, diferenciando-se da ansiedade e angustia que não se referem a objetos específicos, e assim define:

O medo não é uma emoção patologia, mas uma característica universal dos animais superiores e do homem. "Trata-se de um estado de progressiva insegurança e angustia de impotência e invalidez crescente, ante a impressão que sucedera algo que o individuo quer evitar, o que progressivamente se considera menos capaz de fazer”. (DEGLARRONDE, 2008:170).

As manifestações da ansiedade não são desencadeadas exclusivamente pela exposição a uma situação determinada, contudo a exposição a fontes externas de estresses é um importante fator desencadeador dos sintomas. 
Pesquisa realizada sobre a Incidência de stress e fontes estressoras em esposas de portadores da síndrome de dependência do álcool (Lima; Amazonas; Motta. 2007) constatou que 93,53\% das esposas apresentaram stress, sendo 70,96\% com sintomas psicológicos, 19,35\% com sintomas físicos e 3,22\% com sintomas físicos e psicológicos. Como fontes externas de stress, foram identificadas: sobrecarga por assumir todas as responsabilidades na família; falta de apoio em relação à dependência do marido; e agressões verbais por parte dele. Quanto às internas: não perceber alternativas que ajudem na recuperação do marido; sentimento de raiva ao vê-lo alcoolizado; e tensão e preocupação quando ele sai de casa. Os dados apresentados pela pesquisa evidenciam o sofrimento e a sobrecarga emocional, apontando para a necessidade de intervenção junto aos familiares, seja por meio de técnicas do controle de estres ou por meio de outras abordagens.

A depressão se configura como um estado de alterações do humor, tendo como elementos mais salientes o humor triste e o desanimo. "Apresenta uma multiplicidade de sintomas afetivos, instintivos e neurovegetativos, ideativos e cognitivos, relativos à autovalorização, à vontade e à psicomotricidade" (DALGALARRONDO 2008, p.156). Os sintomas mais frequentes apontados Maciel et al (2014) são: humor deprimido, perda de interesse e prazer, redução da energia, fácil estado de exaustão, diminuição das atividades, fadiga em pequenos esforços, redução de concentração e atenção, redução na confiança e na autoestima, sentimento de culpa ou de inconveniência, desânimo e pessimismo em relação ao futuro, ideias ou atos de autodestruição ou suicídio e diminuição do apetite e da libido. Os sintomas depressivos causam prejuízos em várias áreas da vida, como o autocuidado, as responsabilidades cotidianas e o funcionamento social e ocupacional do indivíduo.

Pesquisa realizada por Maciel et al (2014) para verificar a prevalência do sintoma depressivo nos familiares de dependente químico constatou-se um índice de $66 \%$ de sintomatologia depressiva, dos quais $35 \%$ possuíam sintomas leves, $27 \%$, moderados, e $4 \%$, graves.

As pesquisadoras apontam a necessidade de apoio a esses familiares, para que não se sintam desamparados na responsabilidade de cuidar, em casa, do seu familiar dependente químico. Recomendam que as equipes de saúde mental atentem para a realidade das famílias, considerando suas reais condições e propiciando oportunidades de superação das dificuldades e minimização da sobrecarga, de modo que esses familiares se sintam não somente acolhidos, mas assistidos em suas demandas.

A importância da intervenção junto aos familiares de dependentes químicos pode ser visualizada na pesquisa realizada por Maluf (2002) para avaliar de sintomas de depressão e ansiedade em uma amostra de familiares de usuários de drogas que frequentaram grupos de orientação familiar. Nesse estudo foi apontado a diminuição da sintomatologia depressiva após a intervenção. 
Compreende-se assim que a abordagem familiar deve ser considerada como parte do tratamento as pessoas com problemas decorrentes do uso prejudicial e/ou dependência de álcool e outras drogas, uma vez que os familiares também necessitam de cuidado, além da importância do fortalecimento familiar como rede de apoio.

\section{FAMÍlIA NO CONTEXTO DA SAÚDE MENTAL ÁLCOOL E OUTRAS DROGAS}

No campo da campo da saúde mental o tratamento psiquiátrico inclusive para o alcoolismo e outras drogas esteve pautado no modelo asilar caracterizado por longos períodos de internação e afastamento do doente de sua família e do meio social. Historicamente a família não era inserida no tratamento, assumia um papel de informante não cabendo a ela as ações e responsabilidades do cuidado. Mudanças na forma de tratar o doente mental e sua família tiveram inicio no Brasil, em meados de 1970, com a reforma psiquiátrica e desinstitucionalização da doença mental.

No atual contexto político e social, observam-se mudanças significativas no campo da saúde mental, fruto do processo de reforma psiquiátrica, que visa a transformação do modelo clássico de assistência e do paradigma da psiquiatria, efetivado com a promulgação da Lei 10.216:

A Lei 10.216, de 06 de abril de 2001, marco legal da Reforma Psiquiátrica, ratificou, de forma
histórica, as diretrizes básicas que constituem o Sistema Único de Saúde; garante aos usuários de
serviços de saúde mental - e, consequentemente, aos que sofrem por transtornos decorrentes do
consumo de álcool e outras drogas - a universalidade de acesso e direito à assistência, bem como à
sua integralidade; valoriza a descentralização do modelo de atendimento, quando determina a
estruturação de serviços mais próximos do convívio social de seus usuários, configurando redes
assistenciais mais atentas às desigualdades existentes, ajustando de forma equânime e democrática
as suas ações às necessidades da população (BRASIL, 2003).

O centro de Atenção Psicossocial, preconizado como forma de cuidado na saúde mental constituise como serviço substitutivo e não complementar ao hospital psiquiátrico. A Lei 10216 e a portaria 336/2002 (Brasil, 2002) propõem que o centro de atenção psicossocial seja ordenador da rede de atenção as pessoas com transtornos mentais nos municípios. A portaria 336 inclui os CAPS AD como um dos serviços centrais da nova rede substitutiva dos cuidados aos usuários de álcool e outras drogas e instituiu, no âmbito do SUS, o Programa Nacional de Atenção Comunitária Integrada a Usuários de Álcool e Drogas regulamentando as normas e diretrizes para a organização dos CAPS Ad (Brasil 2002).

O CAPS AD oferece atendimento diário por meio da construção de um plano terapêutico dentro de uma perspectiva individualizada e continuada. As atividades desenvolvidas pelos CPAS AD englobam: atendimentos individuais (medicamentoso, psicoterapia, orientação, entre outros), atendimento de grupo, oficinas terapêuticas e visitas domiciliares. Esse tipo de CAPS pode também contar com leitos de repouso com a finalidade exclusiva de tratamento para a desintoxicação. 
$\mathrm{Na}$ atenção psicossocial, o objeto do cuidado das equipes de saúde mental é a unidade familiar em toda sua complexidade, entendendo-a como integrante fundamental no tratamento, na recuperação e no processo de reabilitação psicossocial. Por isso, é imprescindível que a família seja acompanhada pelos serviços substitutivos de saúde mental de maneira que suas necessidades sejam acolhidas conforme mencionado por Mielke, (2010).

O modelo de atenção psicossocial considera o indivíduo como uma pessoa em sofrimento psíquico, que, juntamente com seus familiares e o meio social em que vive, são fundamentais no tratamento. Lourenço e Cardim (2010) mencionam que os primeiros estudos sobre dependência química lançavam seu foco apenas no dependente, não considerando o papel da família e suas implicações nesse processo. Acrescenta ainda que Atualmente os familiares constituem uma excelente fonte de ajuda no tratamento da dependência, a partir do momento em que se considera a família como um sistema que necessita de orientação e acompanhamento para que o resultado do tratamento seja mais eficiente e eficaz, além de reduzir os efeitos negativos em seus membros.

\section{POTENCIAL TERAPÊUTICO NO GRUPO DE MULTIFAMILIARES}

$\mathrm{O}$ atendimento em grupo teve inicio no século passado, por meio de experiências significativas de grupos terapêuticos, estudos sobre o funcionamento e dinâmica de grupos e produção teórica. Desde então, vem sendo cada vez mais reconhecido, em diversas abordagens e orientações teóricas o papel terapêutico dos grupos na produção de saúde.

Uma das primeiras experiências de Grupo terapêutico foi realizada por Jeseph Prat, em 1905. Refere-se ao atendimento a pacientes tuberculosos do hospital geral de Massahusster nos Estados Unidos. Prat realizava reuniões em grupo oferecendo informações sobre a doença e medidas de higiene. Narvaz (2010) menciona que foi observado nesse trabalho, que a tuberculose como doença comum a todos os pacientes favorecia a união e camaradagem.

A abordagem com grupo de familiares iniciou em 1950 a partir dos trabalhos de Lauquer e seus coterapeutas, no contexto hospitalar, tanto com pacientes internados quanto ambulatorial (MORAES, 2008. p. 26). Lauqer reunia 5 a 6 famílias para sessões regulares, nas quais os familiares podiam partilhar suas dificuldades, experiências e trocar sugestões. (NARVAZ, 2010, p.2).

O uso experimental do grupo foi desenvolvido a fim de conhecer o comportamento humano e compreender as leis de funcionamento dos grupos possibilitando a formulação de conceitos teóricos como coesão do grupo, a influência das pressões sociais nos padrões de relação do grupo, coerção, processo de decisão, liderança, afetividade e aprendizagem nos grupos dentre outras, conforme mencionado por Coelho (2008). 
Kurt Lewin considera o grupo "um campo de forças, cuja dinâmica resulta da interação dos componentes em um campo (ou espaço) psicossocial (Coelho, 2008)”. Há na dinâmica dos grupos a presença de duas forças contraditórias: coesão e dispersão que faz com que o grupo se transforme.

O conceito de grupo definindo é definido por Afonso (2003.p.19) “como um conjunto de pessoas unidas entre si porque se colocam objetivos e/ou ideias em comum e se reconhecem interligadas por esses objetivos/ideais". Considera que um grupo deve ter "relações face a face" na qual todos os seus membros se conhecem e reconhecem unidos no grupo. O vinculo formando entre os participantes do grupo devem responder às suas necessidades individuais e grupais e o objetivo do grupo se manifesta pelo interesse dos seus membros em trono de um problema comum (COELHO 2010).

O grupo unido em torno de um objetivo em comum apresentando a mesma problemática é um campo para manifestação da solidariedade criando uma rede de apoio mútuo. Narvaz (2008) coloca que a solidariedade presente nos grupos pode ser compreendida a partir da noção introduzida por Pages (1982): "solidariedade inconsciente que se manifesta nos grupos por intermédio de reações agregarias, baseadas em identificações entre os participantes". "O esforço solidário pode ser compreendido como uma defesa coletiva contra a angústia, reparando os prejuízos causados pelas estruturas sociais constrangedoras" (Narvaz, 2008, p.3) constituindo um importante fator terapêutico do grupo.

Fatores facilitadores da função terapêutica são mencionados por Narvaz (2008): vivência comum do sofrimento; a permissão para falar e sentir livremente em um ambiente acolhedor; a reação de espelho pelas ressonâncias e identificações; a atmosfera de ajuda que favorece a esperança e a experiência emocional corretiva. Destaque especial é dado em relação à solidariedade, a oportunidade troca e ajuda mútua oportuniza ao individuo reconhecer o outro e exercitar a importante capacidade de reconectar-se, sentir-se apoiado e fazer reparações. O campo grupal funciona como uma galeria de espelhos, além de oportunizar as ressonâncias entre as comunicações trazidas pelos diferentes membros (NARVAZ 2008, p.3).

O pesquisador traz ainda a contribuição das experiências de apoio, coesão e autorreflexão que se dão no grupo na promoção de saúde mental.

No grupo, os pacientes experimentam um grande alívio ao descobrirem que não estão sós, que seus problemas são universais e que podem compartilhá-los. "Há, uma ênfase na esperança e na ajuda, o que eleva a autoestima por meio do sentimento de ser útil, altruísta e solidário (Narvaz, 2008. Pg.3).

Segundo Afonso (2003, p.11) "nos grupos, os sujeitos humanos se reconhecem como participantes de uma sociedade, inseridos em uma teia de relações, e papeis sociais, através da qual constroem suas vidas". 
A abordagem familiar em grupo é uma técnica que possibilita um contexto onde os padrões de relacionamento intrafamiliares e os relacionais das famílias com a comunidade podem ser percebidos. Importante característica do grupo mencionada por Moraes (2008) é a de possibilitar aos membros do grupo ver os demais em interação, passando da compreensão particular para a compreensão do outro. Desta forma oportuniza as famílias repensarem os seus conceitos e incluírem-se no projeto de mudança.

O grupo de multifamiliares organiza-se em torno de um problema particular e comum favorecendo a coesão, identificação. Possibilita a expressão de sentimentos e das dificuldades relacionais na dinâmica familiar ao mesmo tempo em que possibilita a partilha de experiências e ajuda mútua. Ravazzola (1997, p.301-302) citado por Narvaz (2010) caracteriza a terapia multifamiliar:

\begin{abstract}
A terapia multifamiliar consiste no encontro de um grupo de famílias com características e modalidades próprias diversas em que estão presentes várias gerações que atuam entre si. Cada participante tem a possibilidade de ver os demais em interação [...]. As famílias se convocam para ajudar a solucionar o problema de uma e de todas, gerando-se um verdadeiro efeito de rede [...]. A presença de outros permite revisar as crenças que cada família sustenta [...] e abre dúvidas acerca dos pressupostos mantidos rigidamente através do tempo [...]. A interação entre pares torna-se facilitadora da mudança. As pessoas se aliviam ao descobrir que outros compartilham seu problema e que transitam por caminhos semelhantes (RAVAZZOLA, 1977, p. 301-302).
\end{abstract}

Segundo Narvaz (2010, p.5) as famílias sintomáticas são famílias que se encontram paralisadas. Pautado no construcionismo social, aponta a importância das perguntas como forma de intervenção nesses sistemas à medida que abre caminho para novas formas de pensar e sentir emergindo novas condutas. Assim o grupo de multifamiliares descortina um novo horizonte ampliando a percepção e compreensão da própria situação e da situação do outro num clima de solidariedade e partilha.

O grupo funciona como uma Equipe Auto reflexiva, cujas intervenções do terapeuta facilitam reflexões e descrições alternativas da realidade e do problema vivenciado, em uma perspectiva de despatologização da linguagem e de resgate dos recursos sadios inerentes a qualquer sistema paralisado. Acreditando nos recursos próprios de cada um (NARVAS, 2010, p. 6).

\title{
5 DISCUSSÃO SOBRE A PRODUÇÃO DE SAÚDE NO GRUPO DE FAMILIARES DO CAPS
} AD

A manifestação do adoecimento familiar e sua interação com a dependência química é tema recorrente nos encontros do grupo de familiares do CAPS ADIII. Os sinais indicativos do sofrimento são identificados na fisionomia, no semblante entristecido, no choro recorrente e nas narrativas dos familiares que rementem a redução da autoestima, impotência diante da dependência química do familiar, isolamento, afastamento das relações sociais, vergonha, pouco investimento para cuidar de si, diminuição nas atividades de lazer, recreativas e sociais. Observa-se também descrença no tratamento e falta de esperança. Relatam exaustão pela convivência prolongada com o dependente químico. 
Esses achados remetem a sintomatologia depressiva que se configura como um estado de alterações do humor, tendo como elementos mais salientes tristeza e desanimo. Para Dalgarrond (2008, p. 156) "a depressão apresenta uma multiplicidade de sintomas afetivos, instintivos e neurovegetativos, ideativos e cognitivos, relativos à autovaloração, à vontade e à psicomotricidade".

Segundo Maciel et al (2014) a família vivencia dificuldades em lidar com o dependente químico trazendo sofrimento, repercutindo em sua saúde mental. No estudo sobre a sintomatologia depressiva nos familiares de dependentes químicos, as pesquisadoras constataram um índice de $66 \%$ de sintomatologia depressiva, dos quais $35 \%$ possuíam sintomas leves, $27 \%$, moderados, e 4\%, graves.

O sentimento de culpa, responsabilização excisava e busca incessante das causas da dependência com questionamento de onde foi que eu errei entram em cena frequentemente. Estão associados a angustia, perdas e lutos, remetendo assim ao que Maruiti (2008) citado por Melo (2014) relacionou como corresponsabilidade pelo processo de adoecimento e pelo tratamento do membro enfermo. Esses sentimentos acarretam a redução da autoestima e muitas vezes estão relacionadas às pressões, sociais, e a própria historia de vida e dinâmica familiar.

A convivência com a dependência química expõe os familiares a vivencia de insegurança, preocupação excessiva, apreensão e medo. Medo inclusive de perder o filho para o tráfico e apreensão de que uma tragédia possa acontecer. Ameaça da morte é recorrente, como também o envolvimento com justiça. Há uma exposição continua às alterações de comportamento do usuário, com episódios de agressividade, violência, entre outros. Muitas vezes o familiar expresso que se sente sugado, tendo que resolve todos os problemas e ainda arcar com as despesas e demais responsabilidades.

Esses temas são abordados pelos familiares com certa frequência, observando-se assim uma relação entre esses fatores e a manifestação da ansiedade e estresse. Remetem a afirmação de Cavalheri (2010) que a vivência com a enfermidade, seja ela de ordem física ou psiquiátrica, é algo complexo e exaustivo para os familiares. Remetem também aos conceitos de medo e ansiedade apresentados por Deglarronde:

\footnotetext{
O medo não é uma emoção patologia, mas uma característica universal dos animais superiores e do homem. Trata-se de um estado de progressiva insegurança e angustia de impotência e invalidez crescente, ante a impressão que sucedera algo que o individuo quer evitar, o que progressivamente se considera menos capaz de fazer (DEGLARRONDE, 2008:170).
}

Ansiedade é definida por Deglarronde (2008) como estado de humor desconfortável, apreensão negativa em relação ao futuro, inquietação interna desagradável inclui manifestações somáticas. Perpassa pelos seguintes sintomas mentais: inquietação interna, medo difuso e impreciso, apreensão desagradável, preocupações exageradas insegurança, irritabilidade, dificuldade para concentrar, insônia. 
As manifestações da ansiedade não são desencadeadas exclusivamente pela exposição a uma situação determinada, contudo a exposição a fontes externas de estresses é um importante fator a ser considerado na convivência familiar com o dependente químico.

A pesquisa sobre o nível de estresse das esposas portadores da síndrome de dependência do álcool (Lima; Amazonas; Motta. 2007) além de constatar elevado índice de estres, identifica como fatores de risco: a sobrecarga por assumir todas as responsabilidades na família falta de apoio em relação à dependência do marido, agressões verbais, tensão e preocupação. Esses fatores condizem com as situações relatadas pelos membros do grupo.

No grupo de familiares, espaço vivo e dinâmico da expressão dos sentimentos e emoções, troca de experiência e busca de ajuda, emerge o seu potencial terapêutico. Com o acolhimento do sofrimento no grupo inicia-se o processo de identificação. Os familiares percebem que não estão sós, que outras famílias passam pelo mesmo problema, às vezes até pior.

A formação do grupo pauta-se na existência de um problema comum, no qual os pacientes se apoiam mutuamente, a fim de encontrarem novas formas de lidar com situação.

\begin{abstract}
A troca de experiência e ajuda mútua oportuniza ao individuo reconhecer o outro e exercitar a importante capacidade de reconectar-se, sentir-se apoiado e fazer reparações. O campo grupal funciona como uma galeria de espelhos, além de oportunizar as ressonâncias entre as comunicações trazidas pelos diferentes membros (NARVAZ 2008, p.3).
\end{abstract}

Os familiares relatam que antes do grupo se sentiam isolados, tinham vergonha do problema além de pensar que seu problema era único e o maior de todos. Reconhecem que no grupo podem "desabafar", falar de seus problemas. "No grupo, os participantes experimentam um grande alívio ao descobrirem que não estão sós, que seus problemas são universais e que podem compartilhá-los. Há, também, uma ênfase na esperança e na ajuda, o que eleva a autoestima por meio do sentimento de ser útil altruísta e solidário" (NARVAZ, 2008. Pg.3).

O grupo de familiares à medida que atende às necessidades dos participantes de obter maior conhecimento sobre a dependência química revela também seu potencial psicoeducativo que reflete positivamente na saúde mental, melhora a comunicação familiar, além de contribuir no processo de inserção ao tratamento.

Aspectos referentes à informação e conhecimentos sobre a dependência química são abordados por meio da conversação em torno da compreensão que os familiares têm de seus próprios dilemas, legitimando o conhecimento que cada um tem de sua experiência vivida, conforme contribuição da abordagem colaborativa. Na construção de conhecimento e promoção de mudança considera-se "o 
processo de conversação que se instala como uma via de duas mãos resulta em uma exploração conjunta e em co-desenvolvimento de novas possibilidades" (GRANDESSO 2009 PG 112).

Familiares discorrem que não tinham conhecimento sobre a dependência química julgava que o dependente era irresponsável, e não deixava o vicio porque não queria. Mencionam que as informações têm ajudado a lidar com o dependente e a mudar a forma de trata-lo. Relatam que compreender e aceitar a dependência química como doença fez com que buscassem ajuda e tratamento para o familiar.

\begin{abstract}
"O grupo psico-educativo esta voltado para trabalhar aspectos de uma situação saúde/doença considerando os fatores sociais, culturais, e psíquicos; promovendo a reflexão, a mudança de mentalidade e reorganização do cotidiano, dando ênfase aos aspectos sócios culturais ou psíquicos que interferem na condição de saúde com também pode promover o esclarecimento de dúvidas, questionamento de mitos, e crenças, informações e conhecimentos." (AFONSO 2003).
\end{abstract}

Lourenço e Cardim (2010) apontam que os familiares constituem uma excelente fonte de ajuda no tratamento da dependência. A família vista como um sistema que necessita de orientação e informação para que o resultado do trabalho seja mais eficiente e eficaz.

À medida que, no grupo de familiares, o foco da saúde mental esta voltado para a família e não para o paciente identificado, cria a oportunidade aos membros do grupo de refletir sobre sua própria condição de saúde. O reconhecimento do adoecimento move o grupo em busca de mudanças e de melhor qualidade de vida e de cuidado com a própria saúde. Nas narrativas reconhecem que também estão doentes e que precisam de tratamento.

No contexto do grupo de familiares observa-se a ajuda mutua na tentativa de resolução de problemas, a crescente troca de experiências e de informação sobre grupos de apoio e serviços de saúde, orientações jurídicas entre outras, que contribuem para ampliação da rede de apoio. Sobre esse aspecto Narvaz (2010) cita Ravazzola (1997): “As famílias se convocam para solucionar o problema de uma e de todas, gerando um verdadeiro efeito de rede".

O modelo sistêmico coloca o foco da atenção na família como um todo, como uma unidade de cuidado considerando que a experiência de cada membro da família afeta o sistema familiar. Nesse sentido a intervenção em grupo de familiares pode produzir efeitos positivos na família abrindo caminho para mudança.

$\mathrm{Na}$ intervenção familiar deve considerar que o dependente químico exerce uma importante função na família, que se organiza para manter a homeostase dentro do sistema, mesmo que para isso a dependência química faça parte de seu funcionamento e muitas vezes a sobriedade pode afetar a homeostase (Cardim; Lourenço; citado por Figlie 2007). Nesse sentido Interpõe-se a seguintes indagações: A intervenção em grupo seria suficiente para clarificar o funcionamento familiar e promover 
mudanças de padrões e interações familiares? Que outras formas de intervenção familiar poderiam ser inseridas na atenção psicossocial a fim de colaborar no processo no processo de mudança?

\section{CONSIDERAÇÕES}

O estudo descritivo sobre o grupo de familiares do CAPS AD III aponta que os familiares de pessoas com problemas decorrentes do uso de álcool apresentam sintomas de depressão, ansiedades, estresses, se sentem desemparados, culpados e com reduzida autoestima.

O grupo de familiares tem revelado seu potencial terapêutico à medida que acolhe o sofrimento favorecendo a exposição da situação problema, a expressão dos sentimentos e emoções num ambiente seguro e protetivo. A identificação grupal, a união em torno de um mesmo problema e um objetivo conjunto tem oportunizado melhoria na qualidade de saúde mental dos familiares.

O grupo contribui para o fortalecimento de vínculos e ampliação da rede de apoio por favorecer a troca de experiência, a ajuda mútua, a construção de estratégias de enfrentamento e a busca de solução.

Nesse sentido o grupo de familiares é um dos dispositivos de atenção psicossocial que contribui na produção de saúde mental dos familiares de dependentes químico. Portando, aponta-se a necessidade de inserir, na atenção psicossocial, outras formas de intervenção familiar que possam colaborar na produção de saúde mental e que possam promover mudanças de padrões e interações familiares.

Por meio deste estudo, reconhece a importância do aporte teórico e metodológico como eixo norteador do trabalho com grupo de familiares, para melhor condução do grupo e acompanhamento dos resultados.

O dispositivo de grupo de familiares paulatinamente vem sendo reconhecido nas politicas e programas de saúde mental, como também despontam estudos que confirmam sua importância. Contudo é preciso maior incentivo e fomento nos estudos e pesquisas a cerca da intervenção familiar a fim de subsidiar os programas e contribuir nas ações práticas realizadas na atenção psicossocial. 


\section{REFERÊNCIAS}

AFONSO, Lúcia (org.); ABADE, Flávia Lemos; et al. Oficinas em dinâmica de grupo na área de saúde. Belo Horizonte: Edições do Campo Social, 2003.255p.

Brasil. (2001). Presidência da República. Casa civil. Subchefia para assuntos jurídicos, Lei 10.216 de 6 de abril de 2001. Brasília ministério da saúde. Disponível em http://www.planalto.gov.br/ccivil03/leis2001/110216.htm

BRASIL. (2002). Ministério da Saúde. Portaria GM nº 336, de 19 de fevereiro de 2002. Define e estabelece diretrizes para o funcionamento dos centros de atenção psicossocial. Brasília: Diário Oficial da União.

BRASIL. (2004). Ministério da Saúde. Saúde mental no SUS: Os centros de atenção psicossocial. Brasília, DF: Ministério da Saúde.

BRASIL. (2012) Ministério da Saúde. Portaria n ${ }^{\circ} 121$, de 25 de janeiro de 2012. Institui a Unidade de Acolhimento para as pessoas com necessidades decorrentes do uso de álcool e outras drogas. Brasília, DF: Ministério da Saúde.

CARDIM, Érika, G.; LOURENÇO. Jumará, S. Intervenções Familiares no tratamento da dependência química.

http://www.uniad.org.br/desenvolvimento/images/stories/publicacoes/ensino/Interv_Familiares_Tratamen to_Dependencia_Quimica.pdf

CAVALHERI, Silvana Chorratt. Transformações do modelo assistencial em saúde mental e seu impacto na família. Rev. bras. enferm.[online]. 2010, vol.63, n.1, pp. 51-57. ISSN 0034-7167. http://dx.doi.org/10.1590/S0034-71672010000100009.

COELHO, Sonia, vieira. Articulando a dinâmica de grupo no processo de atendimento sistêmico de familiares e redes sociais. In: Atendimento sistémico de famílias e redes sociais v.III. $3^{a}$ ed. Belo Horizonte: oficina de arte e prosa 2010. P.480

DALGAlarRONDO, Paulo. Psicopatologia e semiologia dos transtornos mentais. $2^{\text {a }}$ ed. Porto Alegre: Artmed, 2008.p.438.

DEMO, Pedro. Metodologia do conhecimento cientifico. Ed Atlas 2000.p.216

DSM IV Manual diagnóstico dos transtornos Mentais . Ed. Artes Médicas 1994

GRANDESSO, Marilene, A. Desenvolvimento em terapia familiar: das teorias às práticas e das práticas às teorias. In: Manual de terapia familiar; OSORIO, Luiz Carlos e Col. Porto Alegre: Artmed 2009.p. 488

GONÇALVES, Hortência, Abreu de. Manual da metodologia da pesquisa cientifica. São Paulo: Avercamp, 2005. P.142

LIMA, Raitza A.S.; AMAZONAS, Maria Cristina L. de A.; MOTTA, Juliana A. G.Incidência de stress e fontes estressoras em esposas de portadores da síndrome de dependência do álcool. Estudos de Psicologia, Campinas v 24 .n4. p. 431-439 outubro -.dezembro 2007 Disponível em: http://www.scielo.br/pdf/estpsi/v24n4/v24n4a03.pdf 
MACIEL, Silvana C.; MELO, Juliana R.F; DIAS, Camila C.V.; SILVA, Gisele L.S.; GOUVEIA, Yordam B. Sintomas depressivos na família de dependentes químicos. Revista Psicologia: Teoria e Prática, São Paulo, v.16,n 2, p.19-28, maio-agos 2014.disponivem em http://editorarevistas.mackenzie.br/index.php/ptp/article/viewFile/6229/5013

MALUF, Thais Pugliani. Avaliação de sintomas de depressão e ansiedade em uma amostra de familiares de usuários de drogas que frequentaram grupos de orientação familiar em um serviço assistencial para dependentes químicos. 2002. 68f. Disertação (Mestrado em Ciências da Saúde) Programa de Pós- Graduação da Universidade de São Paulo, 2002.Disponível em: http://www.proad.unifesp.br/pdf/dissertacoes_teses/tese_thais.pdf

MINUCHIN, Salvador; FISHMAN CHARLES. Técnicas de terapia familiar. Porto Alegre: Artmed, 1990.p.285.

MIELKE, F, B, et al. A inclusão da Família na Atenção Psicossocial: Uma reflexão. Revista eletrônica enf. Internet. 12(4):761-5 2010

MORAES, Leila Moreira Paiva. Atenção de enfermagem ao familiar do dependente químico: Grupo como estratégia do cuidar. 2008. 243f.Tese ( Doutorado em Enfermagem) Programa de Pós Graduação em enfermagem, Universidade Federal do Ceará, Fortaleza 2008.

NARVAZ, Martha G. Grupos de multifamiliares: história e conceitos. Revista contextos clínicos, São Leoplodo v.3,n. 1 p1-9,janeiro- junho 2010

Disponível em http://pepsic.bvsalud.org/scielo.php?pid=S1983-34822010000100001\&script=sci_arttext

ORTH, Anaídes, P., S., da; Móre, carmem, O.,L. funcionamento das famílias com membros dependentes de substancias psicoativas. Psicol. Argum. 2008 out./dez., 26(55), 293-303, disponível em www 2.pucpr.br/reol/index.php/PA?dd1 $=2525 \& d d 99=$ pdf ace

ORTH, Anaides Pimentel da silva. A dependência química e o funcionamento familiar à luz do pensamento sistêmico. 2005. 159f. Disertação (Mestrado em psicologia) Programa de Pós- Graduação em Psicologia Universidade Federal de Santa Catarina, 2005.

PRATA, Maria M.M. SANTOS, Manoel. Reflexões sobre as relações entre drogadição, adolescência e família: um estudo bibliográfico.

ROSA, Lúcia, C., S. A inclusão da família nos projetos terapêuticos de saúde mental. Psicologia em revista, Belo Horizonte, v. 11, n 18,p.205-208,dez. 2005. Disponível em http://www.pucmg.br/imagedb/documento/DOC_DSC_NOME_ARQUI20060915161333.pdf

SCHENKER, Miriam; MINAYO, Ma Cecilia S. A implicação da família no uso abusivo de drogas: Uma revisão crítica. Ciências e saúde coletiva, v.8, p. 299-306, 2003 Disponível em http://www.scielo.br/pdf/\%0D/csc/v8n1/a22v08n1.pdf

SEADI, Suzana S. M.; OLIVEIRA ,Margareth. A terapia multifamiliar no tratamento da dependência química: um estudo retrospectivo de seis anos. Revista de Psicologia Clinica. Rio de janeiro. PUC, vol.21 n.2. 2009. Disponível em http://dx.doi.org/10.1590/S0103-56652009000200008

SEADI, Suzana M, Satre. A terapia multifamiliar e a dependência química. Dissertação (Mestrado em psicologia Clínica) Programa de Pós Graduação e, Psicologia, Pontifícia da Universidade Católica do Rio Grande Do Sul. Porto Alegre Maço de 2007 
SENAD/CERBRID 2005. II levantamento domiciliar sobre o uso de drogas psicotrópicas no Brasil. Disponível em http://www.cebrid.epm.br/index.php

SILVA, Bruna Larissa cordeiro; ARAÚJO, Alecsconia Pereira; CARVALHO, Rafael Nicolau; MARAES, Marina Nascimento; QUEIROZ, Daiane .Participação da família no tratamento dos usuários do centro de atenção psicossocial de álcool e outras drogas.

Revista brasileira de pesquisa e saúde, Vitória 14(4). 61-68. 2012. Internete.http://periodicos.ufes.br/RBPS/article/viewFile/5120/3846

SUDBRACK, Ma Fátima Oliveira; GUIMARAES Flávio Lobo; COSTA, Liana Fortunato; PESSINA, Luciana Monteiro. Familias, adolescência e drogadição. In: Manual de terapia familiar. Porto Alegre: Artmed 2009.p. 488.

VASCONCELLOS, Ma José, Esteves de. Pensamento sistémico: Uma nova visão nas áreas da saúde, das empresas, da ecologia, das politicas sociais, do direito, das relações internacionais. In: Atendimento sistémico de famílias e redes sociais v.I. $3^{\text {a }}$ ed. Belo Horizonte: oficina de arte e prosa 2012. P.296

VASCONCELLOS, M $\mathrm{M}^{\mathrm{a}}$ José, Esteves de. Pensando sistemicamente nossas relações, a partir do novo paradigma da ciências. In: Atendimento sistémico de famílias e redes sociais. V. I $3^{a}$ ed. Belo Horizonte: oficina de arte e prosa 2012. P.296 